\title{
PRIMER CONGRESO NACIONAL DE MAGISTRADOS DEL PODER JUDICIAL
}

\author{
DECLARACIÓN DE TRUJILLO
}

(06/ 12/ 2007)

Los señores magistrados y servidores del Poder Judicial, participantes en el Primer Congreso Nacional de Magistrados del Poder Judicial, realizado en la ciudad de Trujillo - Sede de la Primera Corte de Justicia del Perú, del 06 al 08 de diciembre de 2007, expresamos a la opinión pública lo siguiente:

1. Renovar nuestro compromiso de apoyar y fortalecer las políticas decambio instauradas por el señor presidente del Poder Judicial.

- Para el cambio institucional es necesario fortalecer actitudes y comportamientos positivos para brindar una justicia eficaz y eficiente, tendiente a satisfacer los requerimientos de acceso y de tutela jurisdiccional efectiva queexigeel Estado Constitucional y democrático deDerecho.

- Erradicar los casos aislados de corrupción que hubieren en el Poder Judicial. Saludamos y reconocemos las políticas instauradas por los Órganos de Gobierno y de Control, respetando los derechos fundamentales del magistrado y/ o auxiliar jurisdiccional.

- Participar activamenteen la ejecución de las políticas sostenidas quese diseñen para una óptima administración de justicia.

2. Respecto a la autonomía del Poder Judicial e independencia de los magistrados en el ejercicio de su función jurisdiccional.

- Por los otros Poderes del Estado conformea la Constitución Políticadel Estado. Cualquier reformaconstitucional oley de desarrollo institucional debe ser consensuada teniendo presente las conclusiones de este Congreso Nacional deM agistrados; asimismo, no deberecortarsenuestro Presupuesto Institucional formulado para el año 2008, sustentado por el Señor Presidente y titular del pliego, que es necesaria para la modernización y cumplimiento de los objetivos trazados en los respectivos planes estratégicos. 
- Rechazar la injerencia de cualquier organismo que afecte la independencia del magistrado en el ejercicio delafunción jurisdiccional, a fin de garantizar estrictamente los principios y derechos establecidos en Ia Constitución Política, para la vigencia de una correcta administración de justicia.

3. Respaldar la gestión del presidentedel Poder Judicial Dr. Francisco Távara eintegrantes del Consejo Ejecutivo del Poder Judicial.

- A poyamos la gestión dela aprobación del Presupuesto del Poder Judicial para el año 2008, así como las gestiones efectuadas con el objeto que se cumpla con la Ley Orgánica del Poder Judicial en lo que respecta al cumplimiento del pago de remuneraciones, bonificaciones y otros beneficios quelecorresponda los magistrados.

- Exigimos conjuntamente con nuestro Presidente, Vocales Supremos y Consejeros, la inclusión dentro del presupuesto de una partida para el cumplimiento de las obligaciones laborales de los magistrados y trabajadores cesantes y jubilados.

- Respal damos las acciones orientadas a la solución y cumplimiento de los redlamos laborales de los auxiliares jurisdiccionales.

- Agradecer la realización de este Primer Congreso Nacional de Magistrados, el mismo quea partir dela fecha debeinstitucionalizarsey ser incluido dentro del programa oficial del Poder Judicial como actividad anual obligatoria; felicitando a los miembros de la Comisión Organizadora deesteCongreso quienes con mucho esfuerzo y dedicación Io han planificado, diseñado y ejecutado acertadamente

- Saludar a la nobley hospitalaria ciudad deTrujillo, sedede estePrimer Congreso Nacional de Magistrados.

- Hacemos extensivo esterespal do a los integrantes dela Sala Plena de la CorteSuprema de Justicia dela República.

4. Nuestro compromiso de ejercer la magistratura observando los principios de calidad y celeridad en la impartición de justicia, promoviendo la utilización de herramientas de justicia, promoviendo la utilización de herramientas modernas de gestión, indicadores y standard que exige la eficacia y eficiencia del servicio de justicia.

Siguen Firmas. 


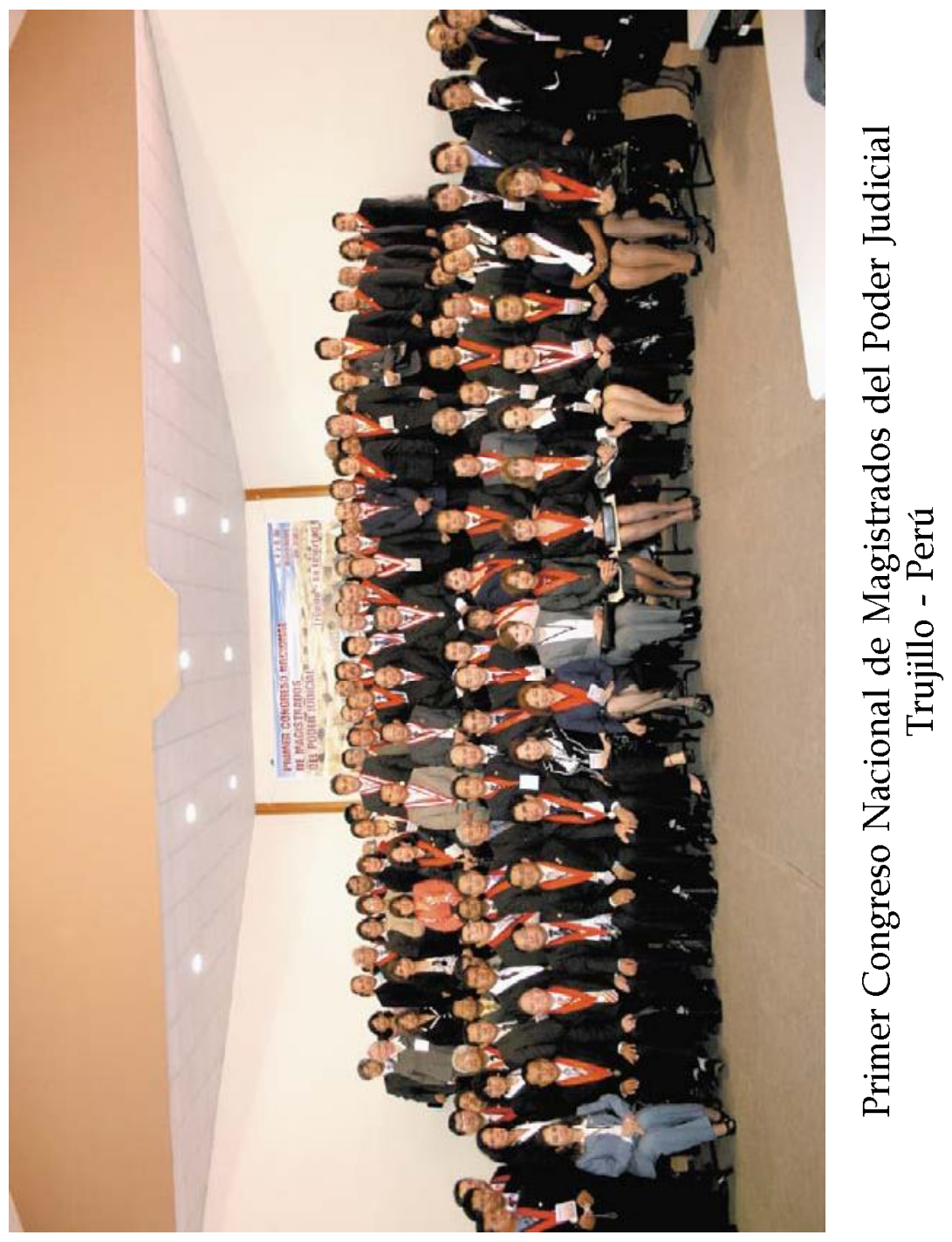

